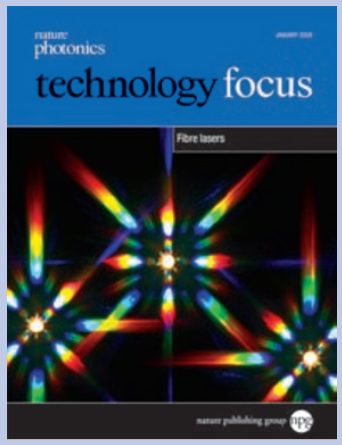

Cover image

The diffraction pattern from a photonic crystal when illuminated by a supercontinuum fibre laser.

Industry Perspective p26

EDITORS: NADYA ANSCOMBE, OLIVER GRAYDON

PRODUCTION EDITOR: CHRIS GILLOCH COPYEDITOR: ANNA DEMMING ART EDITOR: TOM WILSON

naturephoton@nature.com

\title{
Industry's friend
}

M arket-analyst company Strategies Unlimited believes that the fibre laser "represents the most important new technology in the laser industry in a decade," and it's easy to understand why.

The fibre laser is unlike any other laser on the market. Its unique geometry means it is extremely versatile, giving it applications ranging from ophthalmology to welding cars. In this month's Technology Focus, industry experts look at using fibre lasers for marking (see page 21), industrial applications (see page 24) and metrology (see page 26).

Although these articles show that the fibre laser is already being used in commercial applications, there is still much to learn about this fascinating technology and new applications are emerging all the time. Researchers are constantly pushing the parameters to get more out of the fibre laser. Pulses are becoming shorter, pulse energies higher and power scaling is reaching unprecedented levels (see Research Highlights, page 19).

And because of these interesting advances, business is booming and fibrelaser companies are among the fastest growing firms in the laser market.

That said, Andreas Tünnermann, director of the Fraunhofer Institute for Applied Optics and Precision Engineering, believes there are still many challenges ahead (see page 32 ). In his opinion, if industry is going to fully exploit the highpower capabilities of the fibre laser then a challenge for industry is the development of a suitable passive beam-delivery system. However, given the pace of the innovation and improvements in performance it is probable that fibre-laser technology will succeed in rising to the challenges ahead.

\section{RESEARCH HIGHLIGHTS}

19 Millijoule energies, shortest ever pulses, and more

\section{INDUSTRY PERSPECTIVE}

Materials processing: Fibre lasers make their mark Jack Gabzdyl

24 Industrial applications: The allround performer Bill Shiner

26 Metrology: Broad as a lamp, bright as a laser Husain Imam

\section{BUSINESS NEWS \\ 30 Market growth, laser ear surgery, and more}

\section{PRODUCT HIGHLIGHTS \\ $31 \quad$ Higher powers and greater versatility}

\section{INTERVIEW}

\section{2}

\section{Unique geometry}

Interview with

Andreas Tünnermann

\section{nature photonics}

